\title{
Opioid receptor agonists may favorably affect bone mechanical properties in rats with estrogen deficiency-induced osteoporosis
}

\author{
Aleksandra Janas ${ }^{1}$ • Joanna Folwarczna ${ }^{1}$ \\ Received: 13 June 2016 / Accepted: 29 August 2016 / Published online: 28 November 2016 \\ (C) The Author(s) 2016. This article is published with open access at Springerlink.com
}

\begin{abstract}
The results of epidemiological, clinical, and in vivo and in vitro experimental studies on the effect of opioid analgesics on bone are inconsistent. The aim of the present study was to investigate the effect of morphine (an agonist of opioid receptors), buprenorphine (a partial $\mu$ opioid receptor agonist and $\mathrm{K}$ opioid receptor antagonist), and naloxone (an antagonist of opioid receptors) on the skeletal system of female rats in vivo. The experiments were carried out on 3-month-old Wistar rats, divided into two groups: nonovariectomized (intact; NOVX) rats and ovariectomized (OVX) rats. The bilateral ovariectomy was performed 7 days before the start of drug administration. Morphine hydrochloride $(20 \mathrm{mg} / \mathrm{kg} /$ day s.c.), buprenorphine $(0.05 \mathrm{mg} / \mathrm{kg} /$ day s.c.), or naloxone hydrochloride dihydrate ( $2 \mathrm{mg} / \mathrm{kg} /$ day s.c.) were administered for 4 weeks to NOVX and OVX rats. In OVX rats, the use of morphine and buprenorphine counteracted the development of osteoporotic changes in the skeletal system induced by estrogen deficiency. Morphine and buprenorphine beneficially affected also the skeletal system of NOVX rats, but the effects were much weaker than those in OVX rats. Naloxone generally did not affect the rat skeletal system. The results confirmed the role of opioid receptors in the regulation of bone remodeling processes and demonstrated, in experimental conditions, that the use of opioid analgesics at moderate doses may exert beneficial effects on the skeletal system, especially in estrogen deficiency.
\end{abstract}

Keywords Opioids $\cdot$ Osteoporosis $\cdot$ Bone mechanical properties $\cdot$ Rats

Joanna Folwarczna

jfolwarczna@sum.edu.pl

1 Department of Pharmacology, School of Pharmacy with the Division of Laboratory Medicine in Sosnowiec, Medical University of Silesia, Katowice, Poland

\section{Introduction}

There is a progressive increase in the long-term use of opioid analgesics in the treatment of pain associated with cancer and other diseases, such as degenerative changes in the musculoskeletal system (Cherubino et al. 2012). More and more patients, including the elderly, in whom bone mass physiologically decreases, undergo prolonged exposure to opioid analgesics (agonists, partial agonists and agonist-antagonists of opioid receptors) (Ballantyne 2012). This applies particularly to postmenopausal women who are at increased risk of developing osteoporosis due to estrogen deficiency (Braden et al. 2012).

Endogenous opioid peptides and their receptors $(\mu, \delta$, and K) are present in the skeletal system (Baldock et al. 2012; Böhm and Grässel 2012; Spetea 2013), but the role of endogenous opioid peptides in the regulation of bone remodeling processes and the effect of opioid analgesics on the skeletal system have not been fully clarified yet.

Administration of opioid analgesics may adversely affect the skeletal system; however, the results of epidemiological and clinical studies, as well as in vivo and in vitro experimental studies published so far are inconsistent. The populationbased and clinical studies indicate rather damaging effects of opioids on bone leading to a reduction in bone mineral density (BMD) (Pedrazzoni et al. 1993; Kim et al. 2006; Fortin et al. 2008; Dürsteler-MacFarland et al. 2011; Grey et al. 2011; Duarte et al. 2013) and increased risk of fracture (Guo et al. 1998; Ensrud et al. 2003; Vestergaard et al. 2006; Saunders et al. 2010; Solomon et al. 2010; Miller et al. 2011; Carbone et al. 2013; Li et al. 2013), although recently two reports indicating possible favorable opioid effects on the skeletal system in women have been published (Vestergaard et al. 2012; Lee et al. 2013). The unfavorable effects of opioids on the skeletal system are usually attributed to inhibitory effects 
on the endocrine system (hypogonadism), as well as increased tendency to falls (Vestergaard et al. 2006; Daniell 2008; Saunders et al. 2010; Brennan 2013; Duarte et al. 2013); however, results of a small number of in vitro and in vivo experimental studies suggest that opioids may also act directly on bone tissue and exert differential effects (Hall et al. 1996; Pérez-Castrillón et al. 2000; King et al. 2007; Akhoundi et al. 2010; Bastos et al. 2011; Boshra 2011; Ezzatabadipour et al. 2011; Chrastil et al. 2013).

The aim of the present study was to verify, in experimental conditions, the widely held view that opioid analgesics unfavorably affect the skeletal system. The skeletal effects of morphine (an agonist of opioid receptors) and buprenorphine (a partial $\mu$ opioid receptor agonist and a $\mathrm{k}$ opioid receptor antagonist), widely used in the pharmacotherapy of pain, were examined in mature female rats. Moreover, the effects of naloxone (an antagonist of opioid receptors) were studied. Since, due to cessation of ovarian estrogen production in women at menopause, the opioids act on the female organism in different estrogen environment, the present study was conducted in two experimental models: nonovariectomized (with normal levels of estrogen) rats and bilaterally ovariectomized (estrogen-deficient) rats.

\section{Materials and methods}

\section{Animals and chemicals}

The experiments were carried out on 3-month-old female Wistar rats obtained from the Center of Experimental Medicine, Medical University of Silesia, Katowice. The rats were fed a standard laboratory diet Labofeed B (Wytwórnia Pasz "Morawski", Poland). The protocol for the experiments on animals was approved by Local Ethics Commission, Katowice, Poland.

Drugs used were as follows: morphine hydrochloride (substance, Kutnowskie Z.F. "Polfa" S.A.) at a dose $20 \mathrm{mg} / \mathrm{kg}$ s.c. daily; buprenorphine hydrochloride (Bunondol, ampoules, Polfa Warszawa) at a dose $0.05 \mathrm{mg}$ of buprenorphine $/ \mathrm{kg}$ s.c. daily; naloxone hydrochloride dihydrate (substance, SigmaAldrich) at a dose $2 \mathrm{mg} / \mathrm{kg}$ s.c. daily; ketamine (Bioketan, Vetoquinol Biowet); and xylazine (Rometar, Spofa). Morphine and buprenorphine were administered at effective analgesic doses for rats (Mucha et al. 1996; Allen and Dykstra 2000; Curtin et al. 2009). Naloxone was administered at a dose used previously in rats to block the opioid receptors (Farhadinasab et al. 2009).

The studies were carried out on nonovariectomized (NOVX) rats and ovariectomized (OVX) rats (Fig. 1). The rats were acclimated for 7 days after delivery and then divided into experimental groups. The bilateral ovariectomy was performed 7 days before the start of drug administration, under ketamine-xylazine (i.p.) anesthesia. Animals were divided into eight groups: I NOVX control rats $(n=15)$, II NOVX rats treated with morphine $(n=10)$, III NOVX rats treated with buprenorphine $(n=10)$, IV NOVX rats treated with naloxone $(n=10)$, V OVX control rats $(n=15)$, VI OVX rats treated with morphine $(n=10)$, VII OVX rats treated with buprenorphine $(n=10)$, and VIII OVX rats treated with naloxone $(n=10)$. The rats from control groups were given the vehicle $(0.9 \% \mathrm{NaCl}$ solution). The drugs or $0.9 \% \mathrm{NaCl}$ were administered to the rats subcutaneously, once daily for 4 weeks, at a volume of $1 \mathrm{ml} / \mathrm{kg}$.

After 4 weeks of daily administration of the examined drugs, the animals, after overnight fasting, were anesthetized (ketamine-xylazine) and sacrificed by cardiac exsanguination. Blood samples were collected, and after clotting, serum was centrifuged (microcentrifuge type 320) and divided into samples. Samples were stored at $-80{ }^{\circ} \mathrm{C}$. The tibial and femoral bones, and L-4 vertebras, as well as the uterus and thymus were dissected free, and cleaned of soft tissue. The left tibias and femurs were immediately weighed (analytical scale AS 200 S, Ohaus, the accuracy of the measurements $0.1 \mathrm{mg}$ ), and their length and the diameter at the midlength were measured (digital caliper VOREL 15240, Toya, the accuracy of the measurements $0.01 \mathrm{~mm}$ ). The vertebra, uterus, and thymus were weighed.

The left tibia, left femur, L-4 vertebra, and the proximal part of the right femur were wrapped in gauze soaked in $0.9 \% \mathrm{NaCl}$ solution and stored below $-18{ }^{\circ} \mathrm{C}$ for further studies (Turner and Burr 1993).

\section{Bone mechanical properties studies}

The measurements of bone mechanical properties were performed using Instron 3342 apparatus (measuring range 0$500 \mathrm{~N}$ ). To evaluate the mechanical strength of the left femoral diaphysis and left tibial metaphysis, three-point bending tests were performed. A compression test was used to determine the strength of the right femoral neck. The data obtained during the measurements were analyzed using the Bluehill 2 version 2.14 software. The frequency of sampling was $100 \mathrm{~Hz}$.

In the bending tests, values of extrinsic parameters, depending on the dimensions of the bones (load, displacement and the energy, which was absorbed in the range of load from 0 to the given load point) were determined at 3 points: the yield point $(0.05 \%$ offset), the maximum load point, and the fracture point (Fig. 2). The intrinsic parameters, independent of the size of the bones (Young's modulus and stress), were also evaluated.

In order to determine the strength of the left femoral diaphysis, the bone was placed on supporting points (distance $20 \mathrm{~mm}$ ), and the load was directed perpendicularly to the long axis of the femur in the midlength of the bone (Turner and Burr 1993). To obtain steady positioning, the 

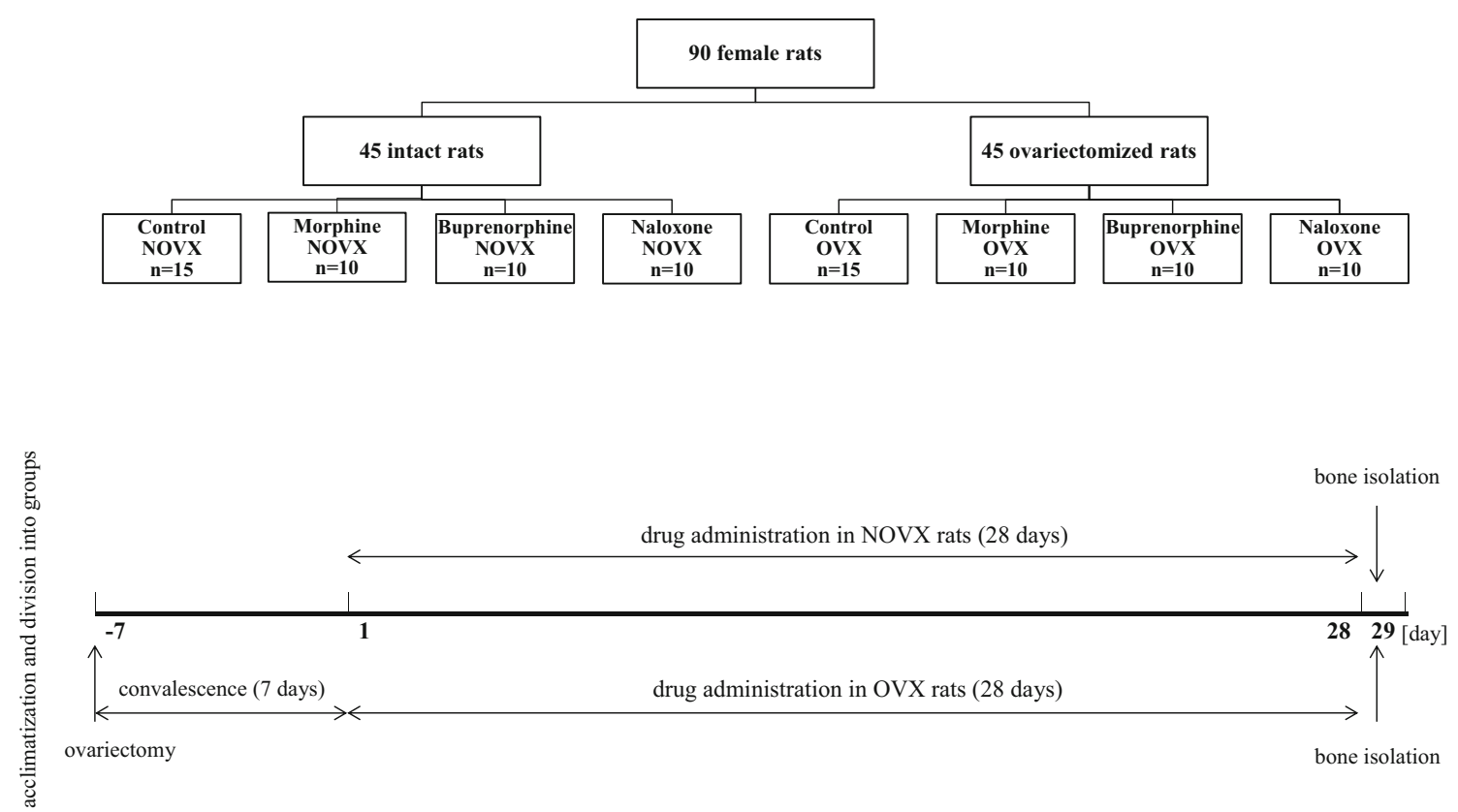

Fig. 1 Group assignments and timeline of the experiments. Morphine hydrochloride $(20 \mathrm{mg} / \mathrm{kg}$ s.c. $)$, buprenorphine hydrochloride (0.05 mg of buprenorphine/ $\mathrm{kg}$ s.c.), and naloxone hydrochloride dihydrate ( $2 \mathrm{mg} / \mathrm{kg}$ s.c.) were administered once daily for 4 weeks

bone was preconditioned (five cycles of the load 0-4 N) (Westbroek et al. 2007; Folwarczna et al. 2013). The displacement rate was $0.01 \mathrm{~mm} / \mathrm{s}$. In order to determine the Young's modulus and the stress values, it was assumed that the femoral diaphysis was an elliptical pipe (Kiebzak et al. 1988). To determine the moment of inertia, necessary for calculations, the transverse cross sections of the right femoral diaphysis were made in the midlength. The internal and external diameters of the diaphysis were measured using Osteomeasure XP v1.3.0.1 software.

The measurement of the strength of the proximal metaphysis of the left tibia was performed by applying the load directed perpendicularly to the long axis of the

a

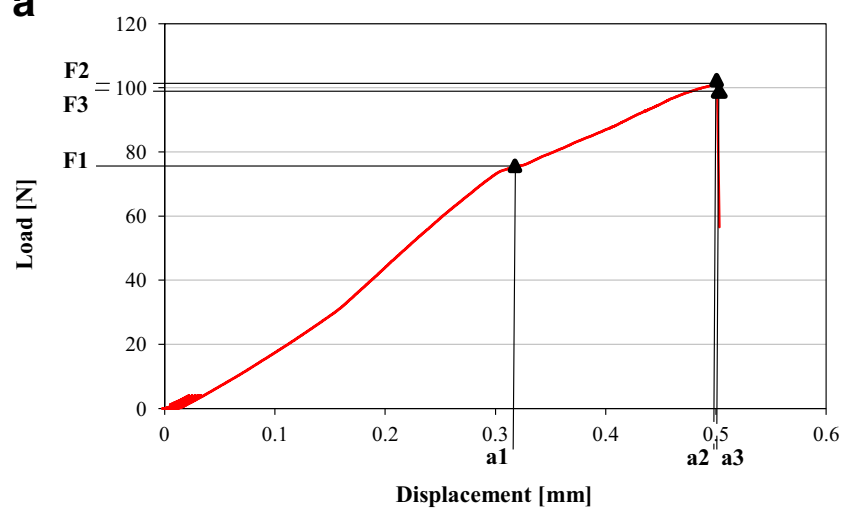

Fig. 2 Load-displacement curves from bone bending tests performed with the use of Instron 3342 apparatus (Bluehill 2 version 2.14 software); a femoral diaphysis, b tibial metaphysis. The load, displacement, energy absorbed, and stress were determined at 3 points: bone, $3 \mathrm{~mm}$ from the edge of the bone deprived of the proximal epiphysis (Stürmer et al. 2006; Folwarczna et al. 2013). The bone was stabilized by pre-load of $1 \mathrm{~N}$. The displacement rate was $0.01 \mathrm{~mm} / \mathrm{s}$. In order to determine the Young's modulus and the stress values, it was assumed that the cross section of the bone at the fracture site had the shape of a circle with a diameter calculated as the mean value of the diameter measured in the frontal and sagittal planes.

To determine the femoral neck strength, the diaphysis, cut at the midlength of the femur, was fixed in a methacrylate plate, and the load was applied to the head of femur (after preload of $1 \mathrm{~N}$ ), with the displacement rate of $0.01 \mathrm{~mm} / \mathrm{s}$

b



the yield point $(0.05 \%$ offset $)$, the maximum load point, and the fracture point (details in the text). $F 1, a 1$-load and displacement at the yield point; $F 2, a 2$ - load and displacement at the maximum load point; $F 3$, a3-load and displacement at the fracture point 
(Pytlik et al. 2004; Folwarczna et al. 2013). The maximum load was measured.

\section{Bone mineralization studies}

The left tibias, left femurs, and L-4 vertebras were ashed at $640{ }^{\circ} \mathrm{C}$ for $48 \mathrm{~h}$ in a muffle furnace and weighed to determine bone mineral mass. The ratio of bone mineral mass to bone mass was calculated. Calcium and phosphorus content in the bone mineral were determined spectrophotometrically, using kits produced by Pointe Scientific, Inc. (Folwarczna et al. 2013). Before measurements, the mineralized bones were dissolved in $6 \mathrm{M} \mathrm{HCl}$ and then diluted in distilled water.

\section{Biochemical studies}

Serum concentrations of biochemical markers of bone formation (osteocalcin) and bone resorption (C-terminal telopeptides of type I collagen (CTX-I)) were measured by enzyme immunoassays (Rat-MID Osteocalcin EIA and RatLaps EIA, respectively, produced by Immunodiagnostic Systems Ltd). Serum tartrate-resistant acid phosphatase $5 \mathrm{~b}$ (TRACP 5b; RatTRAP Assay, Immunodiagnostic Systems Ltd), serum estradiol (Mouse/Rat's Estradiol ELISA, Calbiotech Inc.), and serum calcitonin gene-related peptide (CGRP; Enzyme-linked Immunosorbent Assay Kit For Calcitonin Gene Related Peptide, USCN Life Science Inc.) levels were also determined. Moreover, serum calcium concentration was measured spectrophotometrically, using a kit produced by Pointe Scientific, Inc.

\section{Statistical analysis}

The results are presented as means $\pm \mathrm{SD}$. Kruskal-Wallis ANOVA followed by Mann-Whitney $U$ test were used for statistical evaluation of the results. To evaluate the effects of estrogen deficiency in control rats, the results obtained in the OVX control rats were compared with those of the NOVX control rats. The results obtained in NOVX rats treated with morphine, buprenorphine, or naloxone were compared with those of the NOVX control rats, and the results obtained in OVX rats treated with morphine, buprenorphine, or naloxone were compared with those of the OVX control rats.

\section{Results}

\section{Effects of estrogen deficiency on the skeletal system}

Bilateral ovariectomy caused a profound decrease in the uterus mass/body mass ratio and increases in the thymus mass/ body mass ratio and body mass gain compared to the NOVX control rats (Table 1).

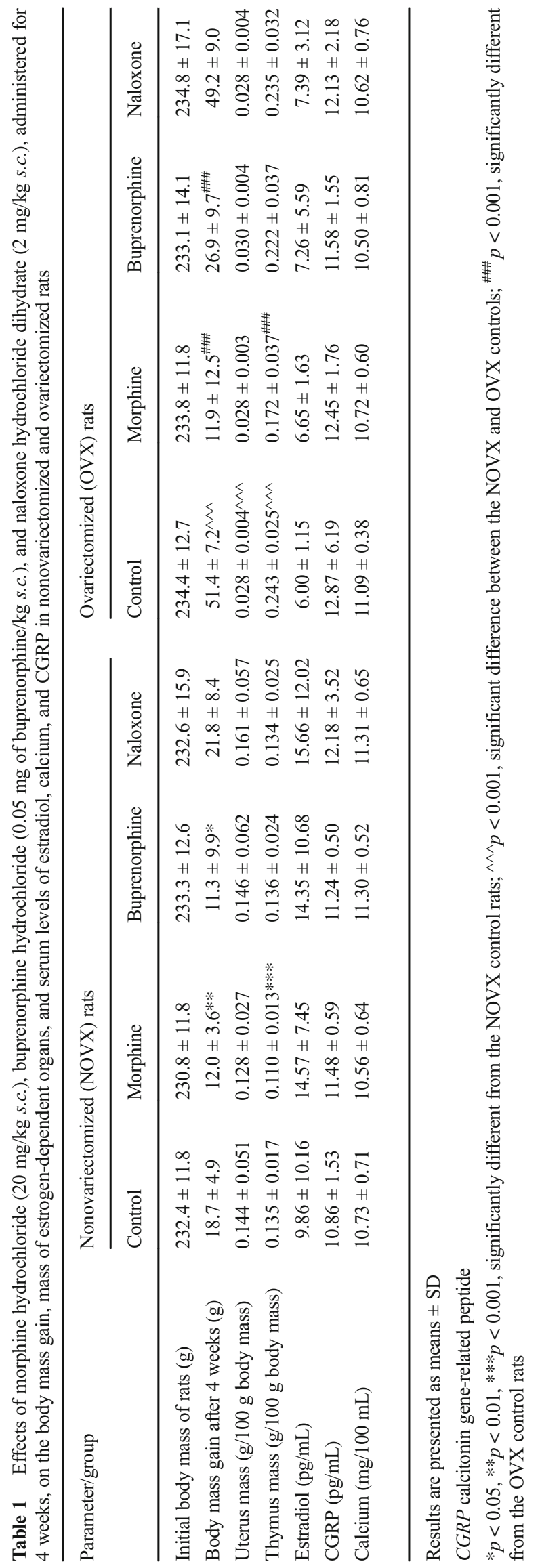


The longitudinal bone growth was intensified in the estrogen-deficient rats (increases in the length of the tibia and femur; Fig. 3). There was no effect of estrogen deficiency on the bone mass and mass of bone mineral (not shown); however, bone mineralization was worsened (there was a significant decrease in the bone mineral mass/bone mass ratio in the L- 4 vertebra and a tendency to decrease the ratio in other bones). The content of calcium and phosphorus in the bone mineral was not altered (Table 2).

Bone turnover was significantly increased in the OVX control rats, as demonstrated by increases in the serum concentrations of osteocalcin (bone formation marker) and CTX-I (bone resorption marker). A decrease in the activity of TRAP $5 \mathrm{~b}$, indicating a reduction in absolute osteoclast number due the decreased bone mass (Rissanen et al. 2008) was also observed (Fig. 4).

The mechanical properties of the tibial metaphysis (mostly cancellous bone) were statistically significantly worsened in relation to the NOVX control rats (Fig. 5, Table 3). Both the extrinsic (load, displacement, energy) and intrinsic (Young's modulus, stress) mechanical parameters were affected. The maximum load and stress as well as load and stress at the fracture point decreased, the corresponding displacement values increased, and the energy


Fig. 3 Effects of morphine hydrochloride (M;20 mg/kg s.c.), buprenorphine hydrochloride ( $B ; 0.05 \mathrm{mg}$ of buprenorphine $/ \mathrm{kg}$ s.c.), and naloxone hydrochloride dihydrate $(N ; 2 \mathrm{mg} / \mathrm{kg}$ s.c. $)$, administered for 4 weeks, on long bone length in nonovariectomized (NOVX) and ovariectomized (OVX) rats. Results are presented as means \pm SD. ${ }^{\wedge} p<0.05,{ }^{\wedge} p<0.01$, significant differences between the NOVX and OVX controls $(C) ; * p<0.05$, significantly different from the NOVX

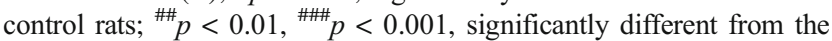
OVX control rats

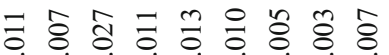



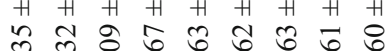

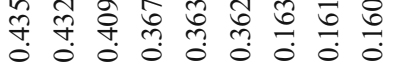

\&े $\begin{array}{lllllllll} & 0 & 0 & 0 & 0 & 0 & 0 & 0 & 0 \\ H & H & H & H & H & H & H & H & H\end{array}$ 年

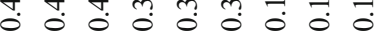

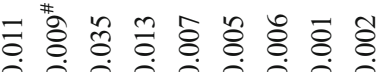

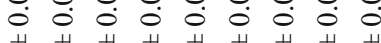
ㄱำ †.

ప $\begin{array}{lllllllll} & 0 & 0 & 0 & 0 & 0 & 0 & 0 & 0 \\ 0_{H} & H & H & H & H & H & H & H & H\end{array}$ そ) サ.

華







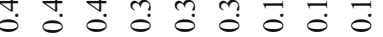





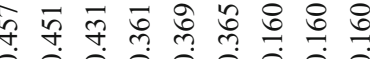

艺 \&

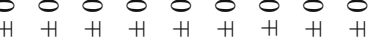

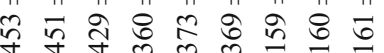



응 ప









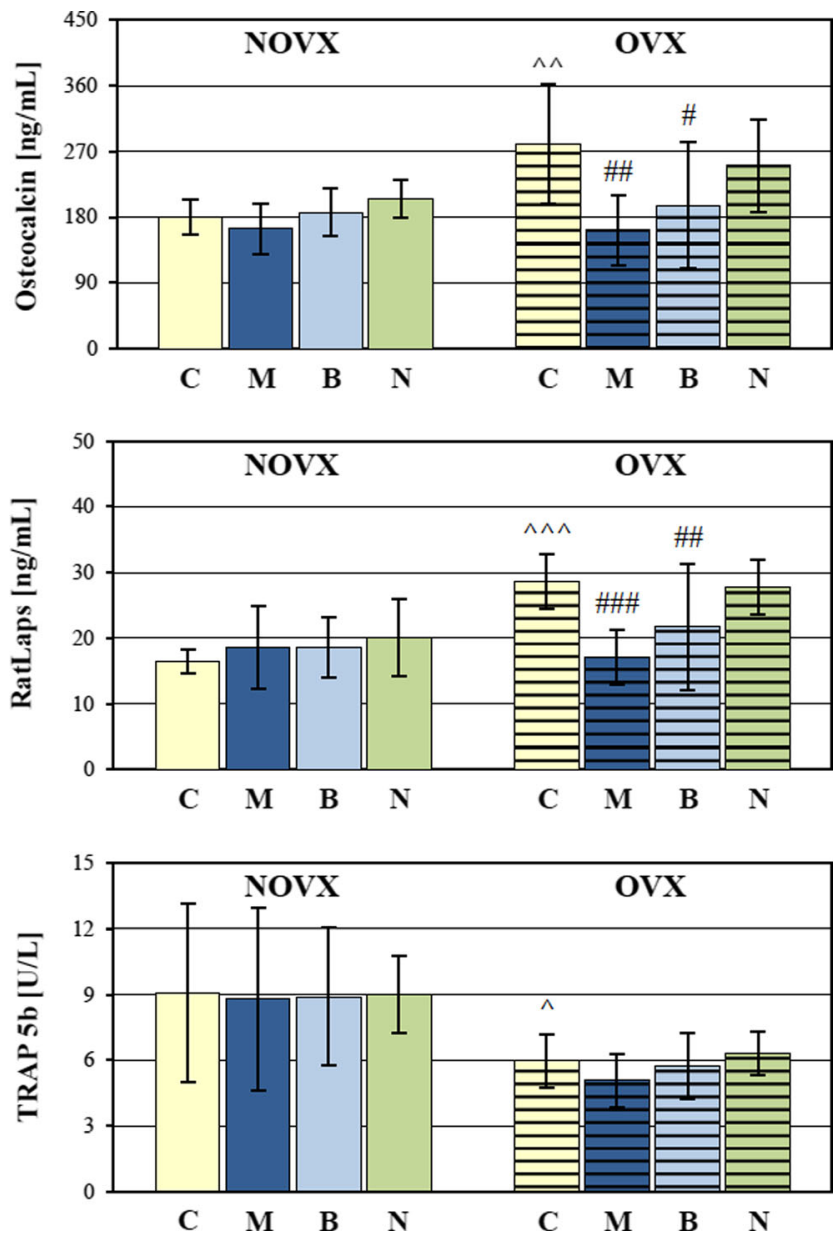

Fig. 4 Effects of morphine hydrochloride ( $M ; 20 \mathrm{mg} / \mathrm{kg}$ s.c. $)$, buprenorphine hydrochloride (B; $0.05 \mathrm{mg}$ of buprenorphine $/ \mathrm{kg}$ s.c.), and naloxone hydrochloride dihydrate ( $N ; 2 \mathrm{mg} / \mathrm{kg}$ s.c.), administered for 4 weeks, on serum levels of bone turnover markers in nonovariectomized (NOVX) and ovariectomized (OVX) rats. Results are presented as means $\pm \mathrm{SD}$. RatLaps C-terminal telopeptides of type I collagen released during bone resorption, TRAP tartrate-resistant acid phosphatase. ${ }^{\wedge} p<0.05,{ }^{\wedge} p<0.01,{ }^{\wedge} \wedge p<0.001$, significant differences between the NOVX and OVX controls $(C) ;{ }^{\#} p<0.05,{ }^{\# \#} p<0.01$,

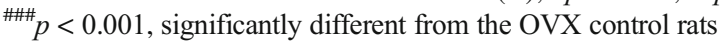

absorbed to the maximum load decreased. Similar effects were observed at the yield point (not shown). Young's modulus was also decreased. Estrogen deficiency did not affect the mechanical properties of cortical bone of the femoral diaphysis. The strength of the femoral neck (built of cortical and cancellous bone) was not significantly affected (Table 3).

\section{Effects of morphine on the skeletal system}

Administration of morphine hydrochloride ( $20 \mathrm{mg} / \mathrm{kg}$ s.c.) for 4 weeks to NOVX and OVX rats decreased the body mass gain (Table 1), in relation to the corresponding control rats. There was no effect on the serum concentration of estradiol and the uterus mass/body mass ratio, but after administration of morphine, the thymus mass/body mass ratio significantly decreased. The use of morphine did not affect the serum level of CGRP. Administration of morphine to NOVX and OVX rats reduced the longitudinal growth of the femur (Fig. 3), without affecting bone mass (not shown).

In rats receiving morphine, bone mineralization was intensified, as evidenced by statistically significant increase in the ratio of bone mineral mass to bone mass in the femur of NOVX rats and in the tibia of OVX rats. There was no effect on the content of calcium and phosphorus in the bone mineral (Table 2).

The use of morphine did not statistically significantly affect the serum levels of bone turnover markers (osteocalcin, CTX-I, and TRAP 5b) in NOVX rats (Fig. 4). In OVX rats, concentrations of osteocalcin and CTX-I were statistically decreased. Morphine did not affect the serum calcium level (Table 1).

Administration of morphine to NOVX rats resulted in the increase in the maximum load applied to the tibial metaphysis, without other significant effects on bone mechanical properties (Fig. 5, Table 3). In estrogen-deficient (OVX) rats, Young's modulus of the tibial metaphysis increased to the values of the NOVX control rats. The maximum load and stress, and the load at the fracture point statistically significantly increased in comparison with the OVX control rats. The values of energy absorbed to these points did not change, compared to the results obtained in the OVX control rats, due to the reduction in the displacement values. There was no effect of morphine on mechanical parameters of the femoral diaphysis and neck (Table 3).

\section{Effects of buprenorphine on the skeletal system}

Administration of buprenorphine $(0.05 \mathrm{mg} / \mathrm{kg}$ s.c. $)$ for 4 weeks to NOVX and OVX rats decreased the body mass gain and did not affect the serum estradiol concentration, and the ratios of mass of the uterus and thymus to the body mass in relation to the corresponding control rats (Table 1). Buprenorphine did not affect the longitudinal growth of the tibia and femur (Fig. 3).

Bone mineralization was improved after administration of buprenorphine (as evidenced by statistically significant increases in the ratio of bone mineral mass to bone mass in the femur of NOVX rats, and in the tibia and L-4 vertebra of OVX rats; Table 2). The content of calcium and phosphorus in the bone mineral was not changed in relation to the appropriate controls (Table 2).

Administration of buprenorphine did not affect the serum bone turnover markers in NOVX rats. In OVX rats, the levels of osteocalcin and CTX-I statistically significantly decreased in comparison to the OVX control rats (Fig. 4). There was no effect of buprenorphine on the serum levels of TRAP $5 b$ and calcium (Table 1). 

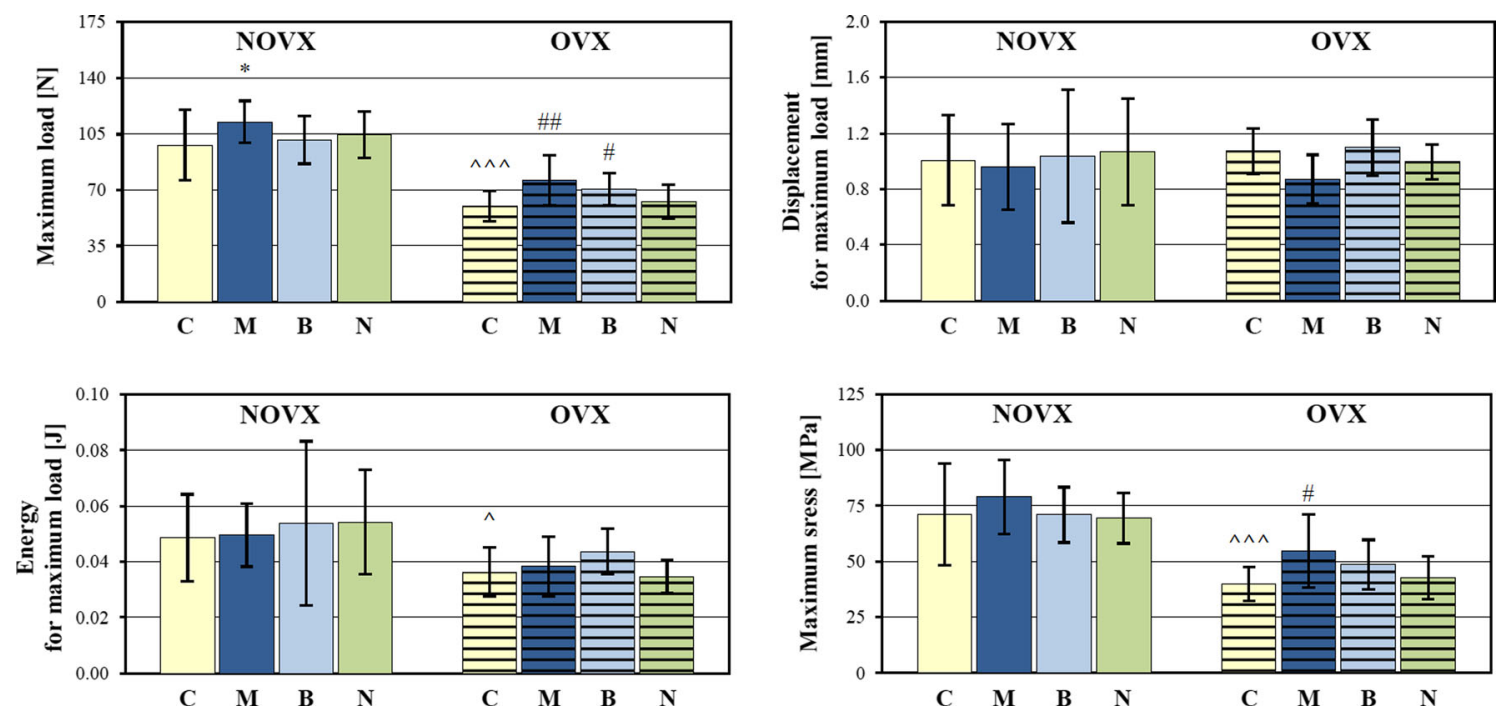

Fig. 5 Effects of morphine hydrochloride ( $M ; 20 \mathrm{mg} / \mathrm{kg}$ s.c.), buprenorphine hydrochloride (B; $0.05 \mathrm{mg}$ of buprenorphine $/ \mathrm{kg}$ s.c.), and naloxone hydrochloride dihydrate $(N ; 2 \mathrm{mg} / \mathrm{kg}$ s.c.), administered for 4 weeks, on mechanical properties of the tibial metaphysis (parameters for the maximum load point) in nonovariectomized (NOVX) and

ovariectomized (OVX) rats. Results are presented as means \pm SD. ${ }^{\wedge} p<0.05,{ }^{\wedge \wedge} p<0.001$, significant differences between the NOVX and OVX controls $(C) ; * p<0.05$, significantly different from the NOVX control rats; ${ }^{\#} p<0.05,{ }^{\#} p<0.01$, significantly different from the OVX control rats

The use of buprenorphine did not affect the mechanical properties of the tibial metaphysis in NOVX rats (Fig. 5, Table 3). In OVX rats, administration of buprenorphine induced significant increases in the maximum load applied to the tibial metaphysis (Fig. 5) and in the load and stress at the fracture point (Table 3), counteracting the effects of estrogen deficiency. Administration of buprenorphine did not affect the mechanical properties of the femoral diaphysis and neck both in NOVX and OVX rats (Table 3).

\section{Effects of naloxone on the skeletal system}

Administration of naloxone hydrochloride dihydrate $(2 \mathrm{mg} / \mathrm{kg}$ s.c.) for 4 weeks to NOVX and OVX rats did not affect the body mass gain, the serum concentration of estradiol, and the ratios of the uterus and thymus mass to the body mass in relation to the corresponding control rats (Table 1). Naloxone did not affect the longitudinal growth of the tibia and femur (Fig. 3).

Administration of naloxone in NOVX rats induced increases in the ratio of bone mineral mass to bone mass in the femur (statistically significant) and L-4 vertebra (Table 2). There was no effect of naloxone on the bone mineral mass/ bone mass ratio in OVX rats. Naloxone did not significantly affect calcium and phosphorus content in the bone mineral (Table 2).

Administration of naloxone did not affect the serum bone turnover markers and calcium levels both in NOVX and OVX rats (Fig. 4, Table 1).

Naloxone did not affect the mechanical properties of the tibial metaphysis in NOVX rats (Fig. 5, Table 3). In OVX rats,

the fracture point load increased and the values of displacement and energy decreased in relation to the OVX control rats (Table 3). Administration of naloxone did not affect the mechanical properties of the femoral diaphysis and neck both in NOVX and OVX rats (Table 3).

\section{Discussion}

The effects of drugs acting through opioid receptors on the skeletal system, investigated in the present study, did not confirm the damaging action of opioid analgesics, which might have been expected based on the literature. In fact, beneficial effects of morphine and buprenorphine in rats with estrogen deficiency were observed. A similar, though weaker, effects were present in rats with normal estrogen levels. Administration of an opioid receptor antagonist, naloxone, did not exert opposite effects to those induced by the investigated opioid analgesics.

The only unfavorable effect of morphine on the skeletal system in the present study was the inhibition of the longitudinal growth of the tibia and femur, concurrently with the decrease in body mass gain. The inhibition was observed both in NOVX and OVX rats. Consistently, a reduction in the number of cells in the proliferation zone of the growth plate (and the growth plate width) under the influence of morphine was demonstrated in young rats (Ezzatabadipour et al. 2011). Also, a restriction of fetal growth often occurs during pregnancy in opioid-dependent women, although numerous studies have demonstrated the stimulatory effect of opioids on the 


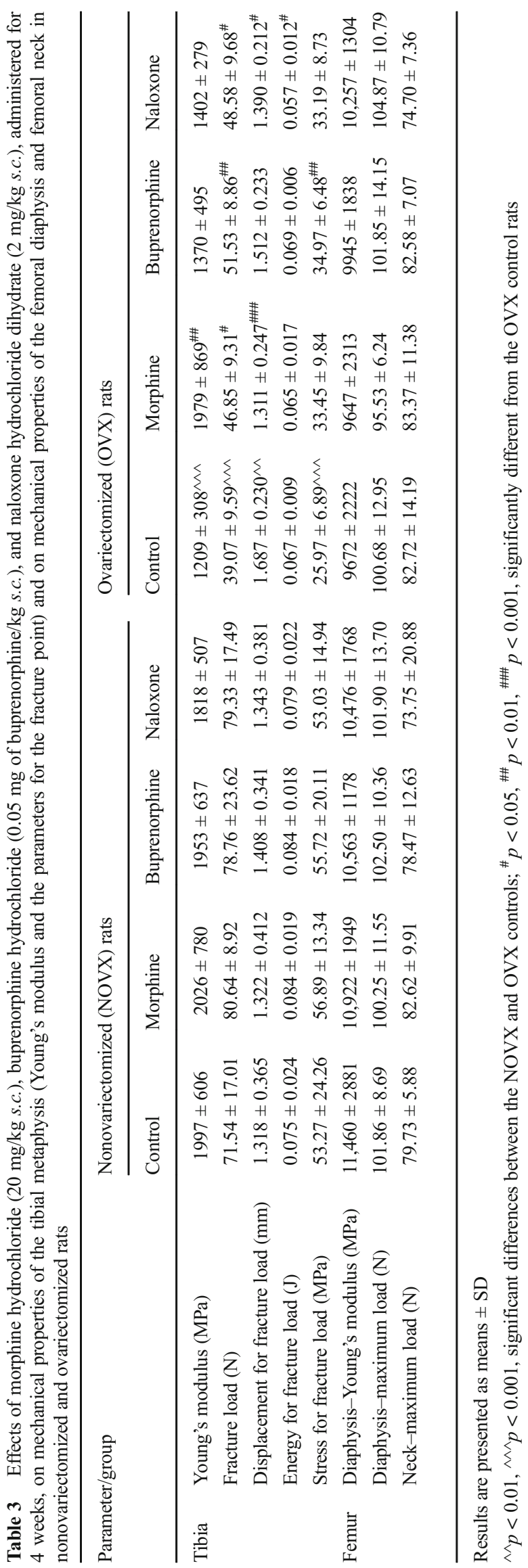

secretion of growth hormone (Olsen et al. 2014). Neither buprenorphine, a partial $\mu$ receptor agonist and $\kappa$ receptor antagonist, nor naloxone, an opioid receptor antagonist, affected the longitudinal bone growth. Also, bone growth was not affected in Dyn-/- mice lacking dynorphin (which act mainly through $\mathrm{K}$ receptors) expression (Baldock et al. 2012).

Morphine and buprenorphine counteracted the development of osteoporotic changes in the skeletal system of OVX rats. Estrogen deficiency in rats, similarly as in postmenopausal women, leads to increased bone remodeling processes with the predominance of resorption over formation, and cancellous bone is more affected than compact bone (Lelovas et al. 2008). This was confirmed in the present study; both bone formation and bone resorption were increased, and bone mineralization was impaired in OVX rats. These changes led to worsening of mechanical properties of cancellous bone of the tibial metaphysis.

After administration of the opioid agonists to OVX rats, bone turnover rate slowed down, as demonstrated by significant reduction of bone formation and bone resorption markers. Also, bone mineralization was improved. These activities led to the increase in the strength of the tibial metaphysis (cancellous bone). Both drugs did not affect mechanical properties of the femoral diaphysis (cortical bone) and neck (cortical and cancellous bone). The effects of opioid agonists on the skeletal system of NOVX rats were limited to the improvement of bone mineralization (morphine and buprenorphine) and mechanical properties of cancellous bone (morphine).

Although long-term use of opioids in humans leads to the development of hypogonadism, administration of morphine, buprenorphine, and naloxone in the present study did not affect the serum estradiol level and uterus mass/body mass ratio. In fact, the skeletal effects of morphine and buprenorphine in OVX rats were similar to those induced by estradiol supplementation in our previous studies (Folwarczna et al. 2009; Cegieła et al. 2012). Taken together, drugs acting through opioid receptors did not significantly affect the systemic estrogen levels in rats.

Results of the present study are at variance with the widely held view that opioid analgesics unfavorably affect the skeletal system in humans, based on most of previous reports. There are epidemiological data indicating the decreased BMD in patients treated with opioids in relation to nontreated controls (Kim et al. 2006; Dürsteler-MacFarland et al. 2011; Grey et al. 2011; Duarte et al. 2013). Interestingly, the decreased BMD during methadone maintenance therapy was observed in male patients only (Grey et al. 2011). However, those studies did not determine the changes in the skeletal system, and the data were rather not adjusted for other factors, like the treated diseases and poor general health status. Other studies demonstrated that the use of opioid analgesics is associated with an increased risk of fractures, to which the increased risk of falls may contribute (Ensrud et al. 2003; 
Vestergaard et al. 2006; Saunders et al. 2010; Miller et al. 2011; Carbone et al. 2013; Li et al. 2013).

Nevertheless, results of the present study are consistent with recently published reports on the possible favorable opioid effects on the skeletal system in women (Vestergaard et al. 2012; Lee et al. 2013). A small trend to a smaller decline in the spine bone mineral density over 10 years in postmenopausal women using opioids, in comparison to non-exposed, was demonstrated (however with a nonsignificant trend towards more fractures) in Danish Osteoporosis Prevention Study (Vestergaard et al. 2012). It was also demonstrated in a population-based nested case-control study that morphine tends to exert the protective action on the skeletal system of female patients with cancer. The use of morphine in patients treated with bisphosphonates significantly reduced the risk of osteoporosis (compared with patients on bisphosphonates only) (Lee et al. 2013). Results of these studies indicate on the possibility of favorable direct opioid effects on bones.

Previous experimental studies demonstrated rather bonedamaging effects of opioid receptor agonists. The development of osteoporosis in rats was reported after 3-month administration of morphine at a lower dose (Boshra 2011); the author associated the skeletal changes with reduced levels of estrogen, not observed in the present study. Morphine unfavorably affected the skeletal system in mice with experimental sarcoma, with no influence on control animals (King et al. 2007). The inhibition of fracture healing by morphine was demonstrated in rats; this effect, however, was associated with inhibition of callus resorption (Chrastil et al. 2013). Morphine inhibited the orthodontic movement of teeth in rats, which also indicates the inhibition of bone resorption (Akhoundi et al. 2010), consistently with results of the present study (inhibition of bone resorption by morphine and buprenorphine).

The mechanism of the beneficial effect of morphine and buprenorphine observed in the present study may be associated with their direct effects on opioid receptors in bone cells. All opioid receptors were demonstrated to be present in human osteoblast-like MG-63 cells (Pérez-Castrillón et al. 2000). The stimulation of opioid receptors leads to the inhibition of adenylate cyclase and reduction of the cellular cAMP level (Al-Hasani and Bruchas 2011). Since increased cAMP levels (for example induced by parathormone) activate cAMP-dependent protein kinase A in marrow stromal cells and osteoblasts, inducing both bone formation and bone resorption (the latter by stimulating the secretion of RANKL) (Kondo et al. 2002; Wang et al. 2006), it is possible that decreased bone turnover induced by the opioid analgesics may be due to the reduced level of cAMP in osteoblasts. Similar actions of morphine (an agonist of $\mu, \delta$, and $\kappa$ receptors) and buprenorphine (a partial $\mu$ receptor agonist and $\kappa$ receptor antagonist) suggest the responsibility of $\mu$ receptors for the observed effects. Also, based on the results of Baldock et al. (2012), the antagonistic effect on $\mathrm{K}$ receptors could contribute to the beneficial effects of buprenorphine in present study.
In search of the mechanism of action of the opioid analgesics on bones, serum CGRP levels were determined. CGRP, apart of the involvement in the pain transmission and modulation, directly affects bone cells, increasing bone formation and decreasing bone resorption (Mrak et al. 2010). Although serum CGRP levels in OVX rats slightly increased in relation to NOVX controls, in accordance with higher CGRP levels in postmenopausal than in premenopausal women (Gupta et al. 2008), there was no effect of the opioids on the serum CGRP level.

A surprising result of the present study is the observation that naloxone not only did not exert opposite to morphine and buprenorphine effects but also affected some parameters similarly to the opioid receptor agonists. The administration of naloxone to OVX rats increased the fracture point load in cancellous bone of the tibial metaphysis; in NOVX rats, there was an increase in the femur mineralization. The improvement of some bone parameters induced by naloxone in rats is consistent with the effect of administration of low-dose naloxone in the sheep: increased mineralization and callus remodeling in a model of bone damage (Petrizzi et al. 2007). However, the reports on effects of opioid receptor antagonists on bone resorption are inconsistent; naltrexone caused a decrease of orthodontic tooth movement in rats with experimentally induced cholestasis (Nilforoushan et al. 2002), and the topical application of naloxone intensified alveolar bone loss in experimentally induced periodontitis in rats (Queiroz-Junior et al. 2013).

The lack of opposing effect of naloxone in relation to morphine and buprenorphine may be due to the fact that the naloxone dose chosen as the dose blocking opioid receptors, might lead to agonistic effects within the skeletal system. It has been shown that naloxone in small doses has an analgesic effect in humans and animals (Petrizzi et al. 2007). Due to the enormous complexity of the endogenous opioid peptide system, and opioid receptors, it is possible that the use of naloxone at a particular dosage may differentially modify the action of individual peptides. For example, the Dyn-l- mice had increased bone formation markers, which indicates that dynorphin inhibits bone formation (Baldock et al. 2012). Thus, blocking of $k$ receptors by naloxone and buprenorphine may lead to improvement of certain parameters related to bone formation.

The significance of the study is that it for the first time reports on the favorable effects of opioid receptor agonists (morphine and buprenorphine), used in the therapeutic dose range, on the skeletal system in female rats, especially in conditions of estrogen deficiency. Results of the study, indicating the improvement in bone mechanical properties and mineralization by the opioid analgesics, support and provide the experimental background for the isolated so far observations made in female patients indicating some positive skeletal effects of opioids on bone (Vestergaard et al. 2012; Lee et al. 
2013). Based on the results of the present study, it seems likely that opioids also in humans may not only not damage the skeletal system but also exert some direct favorable effects, which are counteracted by indirect detrimental ones. This seems to be important in the light of numerous, both reasonable and unfounded, concerns over the use of the opioid analgesics in the long-term therapy of pain.

The limitation of the study is that it concerns the experimental conditions in rats only and does not provide the data on the bone microstructure. Moreover, since the three drugs differently affecting opioid receptors were investigated at one dose each, and there was one duration (4 weeks) of drug administration, results of the study do not exclude the possibility of unfavorable skeletal effects of opioids used in larger doses and for longer duration. It is also possible that the beneficial effects of opioid analgesic drugs may be limited to females. Taken together, the study may be treated as preliminary one.

In conclusion, results of the present study confirmed the role of opioid receptors in the regulation of bone remodeling processes and demonstrated, in experimental conditions, that the use of opioid analgesics at moderate doses may have beneficial effects on the skeletal system, especially in estrogen deficiency. Since the favorable opioid effects were demonstrated in female rats, and some positive skeletal effects were reported in female patients, it seems interesting to answer the question whether the effects of opioid analgesics on the skeletal system depend on sex.

Acknowledgments The study was performed using financial means of Medical University of Silesia, Katowice.

Compliance with ethical standards The protocol for the experiments on animals was approved by Local Ethics Commission, Katowice, Poland.

Conflict of interest The authors declare that they have no conflict of interest.

Open Access This article is distributed under the terms of the Creative Commons Attribution 4.0 International License (http:// creativecommons.org/licenses/by/4.0/), which permits unrestricted use, distribution, and reproduction in any medium, provided you give appropriate credit to the original author(s) and the source, provide a link to the Creative Commons license, and indicate if changes were made.

\section{References}

Akhoundi MS, Dehpour AR, Rashidpour M, Alaeddini M, Kharazifard MJ, Noroozi H (2010) The effect of morphine on orthodontic tooth movement in rats. Aust Orthod J 26:113-118

Al-Hasani R, Bruchas MR (2011) Molecular mechanisms of opioid receptor-dependent signaling and behavior. Anesthesiology 115: $1363-1381$
Allen RM, Dykstra LA (2000) Role of morphine maintenance dose in the development of tolerance and its attenuation by an NMDA receptor antagonist. Psychopharmacology 148:59-65

Baldock PA, Driessler F, Lin S, Wong IP, Shi Y, Yulyaningsih E, Castillo L, Janmaat S, Enriquez RF, Zengin A, Kieffer BL, Schwarzer C, Eisman JA, Sainsbury A, Herzog H (2012) The endogenous opioid dynorphin is required for normal bone homeostasis in mice. Neuropeptides 46:383-394

Ballantyne JC (2012) "Safe and effective when used as directed": the case of chronic use of opioid analgesics. J Med Toxicol 8:417-423

Bastos JV, Queiroz-Junior CM, Caliari MV, Francischi JN, Pacheco CM, Maltos KL (2011) Peripheral kappa opioid receptors activation reduces alveolar bone loss in rats by modulating interleukin- 6 and -10 . Arch Oral Biol 56:540-548

Böhm M, Grässel S (2012) Role of proopiomelanocortin-derived peptides and their receptors in the osteoarticular system: from basic to translational research. Endocr Rev 33:623-651

Boshra V (2011) Evaluation of osteoporosis risk associated with chronic use of morphine, fentanyl and tramadol in adult female rats. Curr Drug Saf 6:159-163

Braden JB, Young A, Sullivan MD, Walitt B, Lacroix AZ, Martin L (2012) Predictors of change in pain and physical functioning among post-menopausal women with recurrent pain conditions in the Women's Health Initiative Observational Cohort. J Pain 13:64-72

Brennan MJ (2013) The effect of opioid therapy on endocrine function. Am J Med 126:12-18

Carbone LD, Chin AS, Lee TA, Burns SP, Svircev JN, Hoenig HM, Akhigbe T, Weaver FM (2013) The association of opioid use with incident lower extremity fractures in spinal cord injury. J Spinal Cord Med 36:91-96

Cegieła U, Folwarczna J, Pytlik M, Zgórka G (2012) Effects of extracts from Trifolium medium L. and Trifolium pratense L. on development of estrogen deficiency-induced osteoporosis in rats. Evid Based Complement Alternat Med 2012:921684 12 pages

Cherubino P, Sarzi-Puttini P, Zuccaro SM, Labianca R (2012) The management of chronic pain in important patient subgroups. Clin Drug Investig 32(Suppl 1):35-44

Chrastil J, Sampson C, Jones KB, Higgins TF (2013) Postoperative opioid administration inhibits bone healing in an animal model. Clin Orthop Relat Res 471:4076-4081

Curtin LI, Grakowsky JA, Suarez M, Thompson AC, DiPirro JM, Martin LB, Kristal MB (2009) Evaluation of buprenorphine in a postoperative pain model in rats. Comp Med 59:60-71

Daniell HW (2008) Opioid endocrinopathy in women consuming prescribed sustained-action opioids for control of nonmalignant pain. $\mathrm{J}$ Pain 9:28-36

Duarte RV, Raphael JH, Southall JL, Labib MH, Whallett AJ, Ashford RL (2013) Hypogonadism and low bone mineral density in patients on long-term intrathecal opioid delivery therapy. BMJ Open 37 pages

Dürsteler-MacFarland KM, Kowalewski R, Bloch N, Wiesbeck GA, Kraenzlin ME, Stohler R (2011) Patients on injectable diacetylmorphine maintenance have low bone mass. Drug Alcohol Rev 30:577-582

Ensrud KE, Blackwell T, Mangione CM, Bowman PJ, Bauer DC, Schwartz A, Hanlon JT, Nevitt MC, Whooley MA, Study of Osteoporotic Fractures Research Group (2003) Central nervous system active medications and risk for fractures in older women. Arch Intern Med 163:949-957

Ezzatabadipour M, Majidi M, Malekpour-Afshar R, Eftekharvaghefi SH, Nematollahi-Mahani SN (2011) The effects of morphine on tissue structure of the growth plate in male rats. Iran J Basic Med Sci 14: $514-520$

Farhadinasab A, Shahidi S, Najafi A, Komaki A (2009) Role of naloxone as an exogenous opioid receptor antagonist in spatial learning and memory of female rats during the estrous cycle. Brain Res 1257:65-74 
Folwarczna J, Zych M, Burczyk J, Trzeciak H, Trzeciak HI (2009) Effects of natural phenolic acids on the skeletal system of ovariectomized rats. Planta Med 75:1567-1572

Folwarczna J, Pytlik M, Zych M, Cegieła U, Kaczmarczyk-Sedlak I, Nowińska B, Sliwiński L (2013) Favorable effect of moderate dose caffeine on the skeletal system in ovariectomized rats. Mol Nutr Food Res 57:1772-1784

Fortin JD, Bailey GM, Vilensky JA (2008) Does opioid use for pain management warrant routine bone mass density screening in men? Pain Physician 11:539-541

Grey A, Rix-Trott K, Horne A, Gamble G, Bolland M, Reid IR (2011) Decreased bone density in men on methadone maintenance therapy. Addiction 106:349-354

Guo Z, Wills P, Viitanen M, Fastbom J, Winblad B (1998) Cognitive impairment, drug use, and the risk of hip fracture in persons over 75 years old: a community-based prospective study. Am J Epidemiol 148:887-892

Gupta P, Harte A, Sturdee DW, Sharma A, Barnett AH, Kumar S, McTernan PG (2008) Effects of menopausal status on circulating calcitonin gene-related peptide and adipokines: implications for insulin resistance and cardiovascular risks. Climacteric 11:364-372

Hall TJ, Jagher B, Schaeublin M, Wiesenberg I (1996) The analgesic drug buprenorphine inhibits osteoclastic bone resorption in vitro, but is proinflammatory in rat adjuvant arthritis. Inflamm Res 45:299-302

Kiebzak GM, Smith R, Howe JC, Gundberg CM, Sacktor B (1988) Bone status of senescent female rats: chemical, morphometric, and biomechanical analyses. J Bone Miner Res 3:439-446

Kim TW, Alford DP, Malabanan A, Holick MF, Samet JH (2006) Low bone density in patients receiving methadone maintenance treatment. Drug Alcohol Depend 85:258-262

King T, Vardanyan A, Majuta L, Melemedjian O, Nagle R, Cress AE, Vanderah TW, Lai J, Porreca F (2007) Morphine treatment accelerates sarcoma-induced bone pain, bone loss, and spontaneous fracture in a murine model of bone cancer. Pain 132:154-168

Kondo H, Guo J, Bringhurst FR (2002) Cyclic adenosine monophosphate/protein kinase A mediates parathyroid hormone/ parathyroid hormone-related protein receptor regulation of osteoclastogenesis and expression of RANKL and osteoprotegerin mRNAs by marrow stromal cells. J Bone Miner Res 17:1667-1679

Lee CW, Muo CH, Liang JA, Chang SN, Chang YJ, Kao CH (2013) Bisphosphonate treatment may reduce osteoporosis risk in female cancer patients with morphine use: a population-based nested casecontrol study. Osteoporos Int 24:2519-2524

Lelovas PP, Xanthos TT, Thoma SE, Lyritis GP, Dontas IA (2008) The laboratory rat as an animal model for osteoporosis research. Comp Med 58:424-430

Li L, Setoguchi S, Cabral H, Jick S (2013) Opioid use for noncancer pain and risk of fracture in adults: a nested case-control study using the general practice research database. Am J Epidemiol 178:559-569

Miller M, Stürmer T, Azrael D, Levin R, Solomon DH (2011) Opioid analgesics and the risk of fractures in older adults with arthritis. J Am Geriatr Soc 59:430-438

Mrak E, Guidobono F, Moro G, Fraschini G, Rubinacci A, Villa I (2010) Calcitonin gene-related peptide (CGRP) inhibits apoptosis in human osteoblasts by $\beta$-catenin stabilization. J Cell Physiol 225:701-708

Mucha RF, Kalant H, Birbaumer N (1996) Loss of tolerance to morphine after a change in route of administration: control of within-session tolerance by interoceptive conditioned stimuli. Psychopharmacology 124: $365-372$

Nilforoushan D, Shirazi M, Dehpour AR (2002) The role of opioid systems on orthodontic tooth movement in cholestatic rats. Angle Orthod 72:476-480
Olsen J, Peroski M, Kiczek M, Grignol G, Merchenthaler I, Dudas B (2014) Intimate associations between the endogenous opiate systems and the growth hormone-releasing hormone system in the human hypothalamus. Neuroscience 258:238-245

Pedrazzoni M, Vescovi PP, Maninetti L, Michelini M, Zaniboni G, Pioli G, Costi D, Alfano FS, Passeri M (1993) Effects of chronic heroin abuse on bone and mineral metabolism. Acta Endocrinol 129:42-45

Pérez-Castrillón JL, Olmos JM, Gómez JJ, Barrallo A, Riancho JA, Perera L, Valero C, Amado JA, González-Macías J (2000) Expression of opioid receptors in osteoblast-like MG-63 cells, and effects of different opioid agonists on alkaline phosphatase and osteocalcin secretion by these cells. Neuroendocrinology 72:187194

Petrizzi L, Mariscoli M, Valbonetti L, Varasano V, Langhoff JD, Von Rechenberg B (2007) Preliminary study on the effect of parenteral naloxone, alone and in association with calcium gluconate, on bone healing in an ovine "drill hole" model system. BMC Musculoskelet Disord 8:43 9 pages

Pytlik M, Folwarczna J, Janiec W (2004) Effects of doxycycline on mechanical properties of bones in rats with ovariectomy-induced osteopenia. Calcif Tissue Int 75:225-230

Queiroz-Junior CM, Maltos KL, Pacheco DF, Silva TA, Albergaria JD, Pacheco CM (2013) Endogenous opioids regulate alveolar bone loss in a periodontal disease model. Life Sci 93:471-477

Rissanen JP, Suominen MI, Peng Z, Halleen JM (2008) Secreted tartrateresistant acid phosphatase $5 \mathrm{~b}$ is a marker of osteoclast number in human osteoclast cultures and the rat ovariectomy model. Calcif Tissue Int 82:108-115

Saunders KW, Dunn KM, Merrill JO, Sullivan M, Weisner C, Braden JB, Psaty BM, Von Korff M (2010) Relationship of opioid use and dosage levels to fractures in older chronic pain patients. J Gen Intern Med 25:310-315

Solomon DH, Rassen JA, Glynn RJ, Garneau K, Levin R, Lee J, Schneeweiss S (2010) The comparative safety of opioids for nonmalignant pain in older adults. Arch Intern Med 170: 1979-1986

Spetea M (2013) Opioid receptors and their ligands in the musculoskeletal system and relevance for pain control. Curr Pharm Des 19: 7382-7390

Stürmer EK, Seidlová-Wuttke D, Sehmisch S, Rack T, Wille J, Frosch KH, Wuttke W, Stürmer KM (2006) Standardized bending and breaking test for the normal and osteoporotic metaphyseal tibias of the rat: effect of estradiol, testosterone, and raloxifene. J Bone Miner Res 21:89-96

Turner CH, Burr DB (1993) Basic biomechanical measurements of bone: a tutorial. Bone 14:595-608

Vestergaard P, Rejnmark L, Mosekilde L (2006) Fracture risk associated with the use of morphine and opiates. J Intern Med 260:76-87

Vestergaard P, Hermann P, Jensen JE, Eiken P, Mosekilde L (2012) Effects of paracetamol, non-steroidal anti-inflammatory drugs, acetylsalicylic acid, and opioids on bone mineral density and risk of fracture: results of the Danish Osteoporosis Prevention Study (DOPS). Osteoporos Int 23:1255-1265

Wang BL, Dai CL, Quan JX, Zhu ZF, Zheng F, Zhang HX, Guo SY, Guo G, Zhang JY, Qiu MC (2006) Parathyroid hormone regulates osterix and Runx2 mRNA expression predominantly through protein kinase A signaling in osteoblast-like cells. J Endocrinol Investig 29:101-108

Westbroek I, Waarsing JH, van Leeuwen JP, Waldum H, Reseland JE, Weinans H, Syversen U, Gustafsson BI (2007) Long-term fluoxetine administration does not result in major changes in bone architecture and strength in growing rats. J Cell Biochem 101:360-368 